\title{
FALSIFICACIONES MEDIEVALES. UNA "BULA" DE NICOLÁS IV FALSIFICADA POR EL REY SANCHO IV DE CASTILLA
}

\author{
Dr. SANTIAGO DOMÍNGUEZ SÁNCHEZ \\ Prof. Titular de la Universidad de León
}

\begin{abstract}
Resumen
En este artículo se hace un estudio analítico de un diplomas del Papa Bonifacio VIII, despachado en 1297, que explica detenidamente por qué otra "bula" anterior de Nicolás IV, dada supuestamente en 1292, es en realidad una falsificación encargada por el rey Sancho IV de Castilla.
\end{abstract}

Palabras clave

Diplomática pontificia. Documentos falsos. Historia medieval castellana. Sancho IV. María de Molina. Nicolás IV. Bonifacio VIII.

\begin{abstract}
In this paper is analyzed a document of the Pope Boniface VIII, sended in the year 1297, that explains why a document of the Pope Nicholas IV, dispatched in 1292, is really a forgery maded by the king Sancho IV of Castille. Keywords

Pontifical diplomatic. Forgeries, false documents. Medieval castilian history. King Sancho IV. Queen Mary of Molina. Pope Nicholas IV. Pope Boniface VIII.
\end{abstract}

Como es bien sabido, desde sus inicios la Diplomática ha tenido como objetivo primario la identificación de los documentos falsos. Efectívamente, la misma definición de esta ciencia que daba su fundador, Mabillon, en el año 1681, es bien representativa de ello: ars secernendi antiqua diplomata vera a falsis.

También es ampliamente conocido que existen distintos tipos de documentos falsos: hay falsos "diplomáticos", aquéllos ilícitamente 
manipulados sólo en sus caracteres formales; y falsos "históricos", en los que la falsedad se refiere al contenido del documento, pudiendo estos últimos ser auténticos diplomáticamente ${ }^{1}$. Ya el citado Mabillon se refería a los diversos tipos de falsos: algunos, que denominaba ex caducitate o ex iactura, se confeccionaban en la Alta y Plena Edad Media casi por obligación, como consecuencia de la pérdida o degradación de un diploma primitivo y de la imposibilidad de obtener un nuevo documento que garantizase ciertos derechos que aquel diploma desaparecido ratificaba solemnemente. Pero también el sabio iniciador de la Diplomática hablaba de los falsos ex dolo malo, aquéllos hechos con mala intención, con intención de engañar y de dejar constancia escrita y firme de negocios jurídicos que no existieron en realidad ${ }^{2}$.

\footnotetext{
${ }^{1}$ Sobre todo en el caso de los llamados falsos de cancillería, confeccionados por empleados cancillerescos sin que el autor del diploma, rey o Papa, estuviese al corriente del hecho.

${ }^{2}$ La bibliografía sobre los falsos es ingente. Destacamos las obras siguientes: J.A. ALEJANDRE GARCÍA, "Estudio histórico del delito de falsedad documental": Anuario de Historia del Derecho español 42 (1972) 117-187; N.P. AZEVEDO, "Documentos falsos de Santa Cruz de Coimbra nos seculos XII-XIII": Revista da universidade de Coimbra 14 (1938); N. BARONE, Intorno alla falsificazione dei documenti ed alla critica di essi, Nápoles 1912; Á. CANELLAS LÓPEZ, "Lo falso en el campo de la Diplomática. Documentos falsos y adulterados de Sancho Ramírez, rey de Aragón y Navarra (1062-1094)": Falsos y falsificaciones diplomáticas en la Edad Media, Zaragoza 1991, 29-36; R. CONDE Y DELGADO DE MOLINA y J. TRENCHS ODENA, "Documentos y sellos falsos de cancillería de la Corona de Aragón: el proceso contra Joan Gil (Valencia 1303)": Falsos y falsificaciones de documentos diplomáticos en la Edad Media, Zaragoza 1991, 37-64; G. DUY, "Les faux dans les archives et les bibliothèques": L'histoire et ses méthodes. Encyclopédie de la Pleyade, París 1961, 1367-1383; F.J. FERNÁNDEZ CONDE, El libro de los testamentos de la catedral de Oviedo, Roma 1971; H. FUHRMANN, "Die fälschungen im mittelalter. Uberlegungen zum mittelalterlischen wahrheitsbegriff": Historische zeitschrift 197 (1963) 529-601; A. GIRY, Manuel de Diplomatique, París 1894, 863-887; O. KURZ, Faux et faussaires, París 1983; F. DE LASALA y P. RABIKAUSKAS, Il documento medievale e moderno. Panorama storico della Diplomatica generale e pontificia, Roma 2003, 115-119; A.R. NATALE, "Falsificazioni e cultura storica e diplomatistica in pergamene santambrosiane del principio all secolo XIII": Archivio Storico Lombardo 1 (1948-1949) 25-42; P. OSTOS SALCEDO y Mª L. PARDO MARTÍNEZ, "La teoría de la falsedad documental en la Corona de Castilla": Falsos y falsificaciones diplomáticas en la Edad Media, Zaragoza 1991, 161-176; J. VON PFLUGK-HARTTUNG, "Päpstliche originalruhunden und scheinoriginäle": Historisches Jahrbuch 5 (1984) 489-575; J. RAMBAUD-BUHOT, Jacques, "La critique des faux dans l'ancien Droit canonique": Bibliothéque de l'École des Chartes 126 (1968) 5-62; M J. SANZ FUENTES, "Aplicación de la crítica documental a un documento falso de Alfonso XI": Anuario de Estudios Medievales 13 (1983) 303-326; ID., "Copias bajo sello y falsificación documental. Un caso ovetense del siglo XIII": Falsos y falsificaciones diplomáticas en la Edad Media, Zaragoza 1991, 177-188; T.F. TOUT, Medieval Forgers and Forgeries, Manchester 1920.
} 
El caso que ahora exponemos es precisamente un ejemplo muy destacado de falso ex dolo malo. Tiene varias particularidades que lo hacen interesante en extremo y paradigmático de documento falso diplomático e histórico por antonomasia.

En primer lugar, se trata de una falsificación muy poco conocida ${ }^{3}$ sobre un asunto de enorme importancia para la corona castellana, puesto que se refiere a la supuesta legitimación en el año 1292, por obra del Pontífice Nicolás IV, del matrimonio habido entre el rey Sancho IV de Castilla y doña María de Molina.

En segundo término, no menor interés tiene otra cuestión: sabemos de la falsedad de dicho documento no porque nosotros $\mathrm{u}$ otro investigador contemporáneo haya hecho un exhaustivo examen diplomático del mismo, sino porque hay dos litterae del Papa Bonifacio VIII, expedidas cinco años después de la falsificación, que explican claramente las razones por las que se debe tener por falso dicho documento, en un ejercicio perfecto de análisis de los hechos, del contenido y de las fórmulas documentales, que nos atrevemos a definir también de crítica diplomática ${ }^{4}$.

Comencemos a explicar el fondo histórico de la cuestión, remitiendo al lector al Apéndice Documental, en el que transcribimos íntegramente, partiendo del Registro Vaticano 48, los diplomas en cuestión.

Sancho IV de Castilla, siendo aún infante, había contraído matrimonio en Toledo, en verano de 1281, con María Alfonso de Meneses, conocida con el tiempo como María de Molina5. Este infante, de carácter impulsivo, había

\footnotetext{
${ }^{3}$ Sólo existe una edición parcial del diploma de Bonifacio VIII que publicamos al final de este artículo, dado en Roma el 3-IV-1297. Se trata, además, de una edición muy antigua y de muy difícil consulta en las bibliotecas españolas: Georges DIGARD, Maurice FAUCON, Robert FAWTIER y Antoine THOMAS, Les Registres de Boniface VIII, I, París 1884, cols. 921-925.

${ }^{4}$ Es conocido otro caso muy similar a éste. Se trata de la "bula" Licet ad regimen, de Inocencio III, dada el 4-IX-1188, "desmontando" paso a paso otra falsificación. Cf. A. POTTHAST, Regesta Pontificum Romanorum inde ab anno 1198 ad annum 1304, I, Berlín 1874, nº 365.

5 Sobre las circunstancias históricas del momento destacamos las siguientes obras: M. GAIBROIS DE BALLESTEROS, Historia del reinado de Sancho IV de Castilla, 3 v., Madrid 1922-1928; ID, María de Molina, tres veces reina, Madrid 1967; A. BENAVIDES, Memorias de don Fernando IV, rey de Castilla, 2 v., Madrid 1860; P. AGUADO BLEYE, Manual de historia de España, I, Madrid 1975, 695-707; V.A. ÁLVAREZ PALENZUELA y L. SUÁREZ FERNÁNDEZ, Historia de España. La consolidación de los reinos hispánicos (1157-1369), Madrid 1988, 93 y ss.; y J.F. O'CALLAHAN, El rey Sabio. El reinado de Alfonso X de Castilla, Sevilla 1996, 307 y ss.
} 
querido celebrar la boda rápidamente, sin preocuparse de ciertos impedimentos: un compromiso matrimonial anterior, que había concertado su padre, Alfonso X, con la rica y noble catalana Guillerma de Moncada; la falta de dispensa pontificia necesaria por la afinidad de parentesco existente entre los esposos, puesto que María de Molina era prima hermana del citado rey Sabio el hecho de que doña María de Molina era pariente de doña María de Ucero, anterior amante de Sancho, y que era, además, madrina de bautizo de una hija de ambos $^{7}$.

La falta de aprobación pontificia de dicha unión ocasionará graves problemas al reino de Castilla, puesto que los hijos de ambos, hasta que llegase la dispensa, serían ilícitos y, por tanto, no podrían ser herederos legales del reino; todo ello, además, en un grave momento de crisis política en la corona castellana, agudizada con los dos polémicos testamentos de Alfonso X el Sabio, que desheredaban a don Sancho y favorecían fundamentalmente a los infantes de la Cerda ${ }^{8}$. A pesar de lo que decía la última voluntad de Alfonso X, muerto éste el 4 de abril de 1284, don Sancho, el mayor de los hijos del rey Sabio, se apresuró a proclamarse rey, junto con su esposa María de Molina, jurándose como heredera a su hija única Isabel ${ }^{9}$, habiendo muy pocas oposiciones a dicha proclamación, a excepción de las de don Juan Núñez de Lara y el infante don $\operatorname{Juan}^{10}$.

Sin embargo, como decíamos, era fundamental para la estabilidad y perdurabilidad del reinado de Sancho IV conseguir la dispensa pontificia para su

\footnotetext{
${ }^{6}$ María de Molina era nieta de Alfonso IX de León, al igual que lo era Alfonso X.

${ }^{7}$ La mejor información sobre estos hechos la proporcionan las crónicas reales de la época. Cf. Crónicas de los reyes de Castilla, desde don Alfonso el Sabio hasta los Católicos don Fernando y doña Isabel, ed. de C. ROSELL, Madrid 1953. También, y aunque mucho más breve, es interesante J. DE LOAYSA, Crónica de los reyes de Castilla, Fernando III, Alfonso X, Sancho IV y Fernando IV, ed. y traducción de A. GARCÍA MARTÍNEZ, Murcia 1982.

${ }^{8}$ Uno de ellos, dado en Sevilla el 8 de noviembre de 1283, desheredaba a los infantes Sancho, Juan, Pedro, Jaime y Manuel por haberse sublevado contra el padre, llamando a la sucesión a sus nietos, Alfonso y Fernando de la Cerda; y en el segundo, dado en la misma ciudad el 22 de enero de 1284, perdonaba a don Juan y a don Jaime, entregaba el reino de Murcia al segundo, y los de Badajoz y Sevilla al primero.

${ }^{9}$ Más tarde, cuando nació un varón, Fernando, se le proclamó heredero a éste.

${ }^{10}$ Sobre este tema, cf. S. DOMÍNGUEZ SÁNCHEZ, "Un diploma del infante don Juan, hijo de Alfonso X, como rey de León, Galicia y Sevilla": Estudios Humanísticos. Geografía, historia, arte 20 (1998) 323-338.

${ }^{11}$ Cf. sobre los documentos de este Papa: F. OLIVIER-MARTIN, Les registres de Martin IV, París 1901, 2a ed., París 1913.
} 
matrimonio. Los hechos se sucedían al contrario, ya que precisamente el Papa Martín IV (1281-1285) ${ }^{11}$ había puesto el reino en entredicho, por dos razones: la rebelión de Sancho contra su padre, Alfonso X, en vida de éste, y el matrimonio inválido del nuevo rey. Las largas gestiones de los procuradores en la Curia pontificia de Sancho IV y María de Molina en pos de la dispensa fracasaron. Lo mismo sucedió nuevamente con los Pontífices posteriores, Honorio IV (1285$1287)^{12}$ y Nicolás IV (1288-1292)

Sancho IV, enfermo de tuberculosis en los últimos años de su vida ${ }^{14}$, intuyendo cercana su muerte, y vista la imposibilidad de conseguir la repetida dispensa, hizo algo insólito: encargó la falsificación de un diploma pontificio que legalizase canónicamente su matrimonio. Hizo el encargo a un personaje del que tenemos pocos datos: un fraile "apóstata y prófugo" de la Orden de Predicadores, llamado Pedro, quien, por su parte, requirió la confección material del diploma falso a un clérigo del que no sabemos ni su nombre, aunque seguramente era italiano ${ }^{15}$. Sin embargo, a pesar del mucho cuidado que ambos pusieron en redactar correctamente el diploma falso, poco después, Bonifacio VIII (1294-1303) descubre los hechos, demuestra quién y cómo se ha ejecutado el diploma falso, y denuncia solemnemente la falsedad de un documento fechado en Roma el 12 de marzo de 1297, el cual, además, tiene el valor añadido para nosotros de insertar íntegramente el documento falso. Finalmente, pocos días después, el 3 de abril de ese mismo año, Bonifacio VIII ordena a los arzobispos de Tarragona y Braga, y al arcediano de Valderas de la catedral de León, que expongan públicamente en sus jurisdicciones y donde crean conveniente los hechos, para que llegue al conocimiento de todos los hispanos la trama.

De este hecho, lógicamente, no dan fe las crónicas de la época, ni tampoco hay rastro alguno en la documentación castellana, por lo que el hecho ha sido desconocido hasta fechas recientes. Sin embargo, como antes anunciábamos, sí ha quedado constancia del mismo entre los fondos del Archivo Vaticano. El folio 372 del Registro Vaticano 48, al registrar estas dos litterae de Bonifacio VIII que acabamos de citar, da buena cuenta del intento de falsificación.

\footnotetext{
${ }^{12}$ Cf. M. PROU, Les registres d'Honorius IV, París 1886-1887.

${ }^{13}$ Cf. E. LANGLOIS, Les registres de Nicolas IV, 2 v., parís 1886-1892, 2ª ed., París 1905.

${ }^{14}$ Moriría en Toledo el 25 de abril de 1295.

${ }^{15}$ Puesto que más adelante confesaría que hizo la falsificación estando en Letrán.
} 
Narraremos ahora sucintamente los hechos puestos de manifiesto en estas dos litterae papales de Bonifacio VIII arriba comentadas, hechos y circunstancias que provocaron "gran escándalo" en la Curia Romana. El clérigo antes citado, compañero de fray Pedro, muy astutamente, había fechado el documento pontificio falso, que imitaba a unas litterae gratiosae, el 25 de marzo de 1292, en Roma, y concretamente en la basílica de Santa María la Mayor, donde Nicolás IV expedía sus diplomas. Era una buena fecha, porque en esos días estaba agonizando este $\mathrm{Papa}^{16}$ y en la Curia pontificia podía pasar bastante desapercibida la expedición de cualquier diploma.

Sin embargo, a Bonifacio VIII no le pasó por alto que entonces, aunque el Papa estuviera moribundo, había un colegio de cardenales, de los que él formaba parte $^{17}$, que deberían haber sido consultados por Nicolás IV para la concesión de la dispensa, o, cuando menos, haber conocido la orden pontificia de expedición de dicha gracia. Bonifacio VIII, en cambio, lo que sí sabía era que, aunque en época del repetido Nicolás IV los reyes Sancho y María de Molina habían intentado repetidamente conseguir la dispensa, ésta no había sido concedida y sí expresamente negada. Además, Nicolás IV había prometido a su Consitorio no dar el visto bueno a este matrimonio sin el consentimiento de los cardenales, y había explicado repetidamente las razones conocidas contra dicha unión: tenían los esposos un tercer grado de consanguineidad, María de Molina era madrina de una hija de Sancho, y ya había esponsales entre Sancho y la noble Guillerma de Moncada, la cual, por su parte, había pedido insistentemente al Papa que no legitimase la unión de Sancho y María de Molina.

A continuación, muy sagazmente y para que no quedasen dudas sobre la posible expedición de un diploma de dispensa en las últimas horas de Nicolás IV, Bonifacio VIII pregunta a los miembros de la Curia y de la Cancillería si conocen la existencia del mismo. En concreto, se hace informar del resto de cardenales, y del camarlengo, del vicecanciller, de los notarios, del auditor litterarum contradictarum, del corrector, del escribano del registro y de otros muchos oficiales ${ }^{18}$ de la Cancillería. Todos responden que no han oído hablar de tal diploma, por lo que Bonifacio VIII concluye que sólo esto ya es un síntoma de falsedad.

\footnotetext{
${ }^{16}$ Que murió el 4 de abril de ese año 1292.

${ }^{17}$ Bonifacio VIII, en marzo de 1292, era cardenal presbítero de los Santos Silvestre y Martino. Cf. C. EUBEL, Hierarchia Catholica, I, Münster 1913, 12.

${ }^{18}$ Lo cual es un buen elenco de los funcionarios que entonces se dedicaban o cuidaban de la expedición de los diplomas papales.
} 
A ello se sumó otra circunstancia: en época de sede vacante (1292-1294) fue capturado y hecho preso cierto clérigo, quien, a las preguntas formuladas poco después por el cardenal Jean Moine, vicencanciller de Bonifacio VIII, confesó que había sido años atrás el ejecutor de la citada falsificación. Declaró, sin coacción alguna, según dicen los diplomas de Bonifacio VIII, que él había confeccionado el diploma falso en Letrán, al poco tiempo de fallecer Nicolás IV, por cierta cantidad de dinero que le había entregado el citado fray Pedro. Además, declaró que ambos habían huido con la falsificación a la ciudad de Savona, en la ribera de Génova, para embarcar en búsqueda del propio Sancho IV, aunque en ese lugar fray Pedro le abandonó. Todo ello indica que fue evidentemente Sancho IV quien pagó y encargó el diploma falso en cuestión.

Tras insertar, como habíamos dicho, las litterae falsas de dispensa, fechadas el 25 de marzo de 1292, Bonifacio VIII recurre a un criterio más que "indica la falsedad y la muestra sin duda alguna". Se trata del análisis interno del diploma falsificado, del que se dice que tiene graves fallos "ex stilo, dictamine, continentia et aliis que in talibus solent atendi". ¿Cuáles son estos errores en el estilo, en el ars dictandi y en el texto? Trataremos de explicarlo.

A pesar de que la redacción del diploma está muy cuidada y trata de seguir el llamado "estilo de la Curia" y de que, puesto que no se dice nada en contra, se habían imitado perfectamente la escritura, el sello y los demás caracteres externos del documento, un análisis detenido del mismo nos revela que hay varios errores:

- En primer lugar, el texto está demasiado enmarañado, especialmente en la expositio. Los documentos pontificios auténticos de esta época son mucho más claros en su narración. Hay expresiones claramente recargadas y anómalas, como "... pura, pia et certa causa dispensamus ...", o "... etiam ex speciali gratia ad uberiorem cautelam legitimantes, legitimam reputantes ...".

- Se incide demasiado y se repite por dos veces un párrafo relativo a lo que más interesaba a Sancho IV: la legitimación de sus hijos, Fernando (IV), Isabel, Pedro y Enrique, reiterando en exceso las razones para dicha gracia.

- Se aducen motivos para la dispensa que nada tienen que ver con el fondo canónico del problema: que el rey ha luchado continuamente contra los sarracenos, que ha entregado cantidades para la Cruzada a Tierra Santa, y que "Cristo derramó su sangre por todos los hombres".

- Se insinúa que se quiere o puede comprar esta dispensa, al decir que el rey entregará como penitencia una buena suma para los gastos de Tierra Santa. 
- Por último, en algunas fórmulas totalmente fijas e inmutables que usa la cancillería pontificia se han introducido variantes que nunca se dan en los diplomas auténticos. Esto se ve claramente en la sanctio típica de las litterae gratiosae. La fórmula obliga a decir "Si quis autem hoc attemptare presmupserit...", expresándose aquí "Si quis autem hanc dispensationem et gratiam nostram attemptare presumpserit...", y, a continuación, en lugar de "... indignationem omnipotentis Dei et beatorum Petri et Pauli, apostolorum eius, se nouerit incursurum", se dice "... indignationem omnipotentis Dei et beatorum Petri et Pauli, apostolorum eius, et nostram, se nouerit incursurum".

Finalizamos este artículo destacando un hecho paradójico, que pone de manifiesto cómo la historia sorprende a los propios interesados: Sancho IV se podía haber ahorrado los gastos, disgustos y humillaciones consecuencia del intento de falsificación, puesto que, a los seis años del fallecimiento de dicho rey, su esposa, María de Molina, tras nuevas gestiones, consiguió del mismo Papa Bonifacio VIII la ansiada dispensa de parentesco, dada en Anagni el 13 de septiembre de $1301^{19}$, quedando legitimada la sucesión del rey Bravo y siendo ello una poderosa arma moral y un fuerte revulsivo para aminorar los graves conflictos que habían tenido lugar en la minoría del hijo de Sancho IV y María, Fernando IV ${ }^{20}$.

19 "Bula" cuya existencia la reina María de Molina conoció en Segovia en otoño de ese mismo año 1301, y que recibió poco después en Burgos. Los portadores del documento papal comunicaron a la reina, de parte del Pontífice, que éste "amábala e preciábala mucho, e decía que, sennaladamente, las gracias que facía, que las facía a la reina, e por ella las facía al rey su fiio". Parece que efectívamente, por esta época, Bonofacio VIII había reconocido los méritos de la reina, puesto que le hacía saber "que, en cuanto él fuese vivo, que pugnase de le demandar las gracias que quisiese, que fuese cierta que ge las daría".

${ }^{20}$ Éste, nacido en Sevilla el 6 de diciembre de 1285, comenzó a reinar con sólo nueve años. Precisamente en ese año, 1301, contando Fernando IV con dieciséis años, fue reconocido mayor de edad en las cortes leonesas de Medina del Campo, y un año después lo sería en las castellanas de Burgos. 


\section{APÉNDICE DOCUMENTAL}

1297, abril, 3. Roma, San Pedro.

Litterae executoriae de Bonifacio VIII comisionando a los arzobispos de Tarragona y Braga, y al arcediano de Valderas en la iglesia de León, para que expongan públicamente en sus jurisdicciones unas litterae solemnes que se insertan, dadas por el propio Pontifice en Roma el 21-III-1297, en las que se denunciaban como falsas unas litterae gratiosae dadas supuestamente por Nicolás IV en Roma el 25-III-1292, dispensando el matrimonio del rey Sancho IV con María de Molina, documento éste que también se inserta.

R. AHV, Reg. Vat. 48, f. 372r-v, al final de la ep. curial núm. 28.

ED. Georges DIGARD y OTROS, Les Registres de Boniface VIII, I, París 1884, cols. 921-925. Parcialmente.

[Bonifatius episcopus, seruus seruorum Dei], venerabilibus fratribus .. terraconensi et .. bracharensi archiepiscopis, et dilecto filio archidiacono de W $/ 41$ alderes in ecclesia legionensi, [salutem et apostolicam benedictionem].

Vt ueritas producatur in lucem, obuietur animarum periculis, multorum dispendiis et scandalis pluri $/{ }^{42}$ morum, ad perpetuam rei memoriam, de fratrum nostrorum consilio, quasdam licteras confici, et bulla nostra bullari fecimus, quarum $/{ }^{43}$ tenor talis est:

Bonifatius episcopus, seruus seruorum Dei, ad perpetuam rei memoriam.

Dudum [tempore uacationis Romane Ecclesie per obitum felicis recordationis Nicolai, Pape IIII, predecessoris nostri, rumore ualido, insinuatione clamosa et fidedignorum assertione multorum ad collegii eiusdem Ecclesie cardinalium, de quorum numero tunc eramus, perducto, notitiam quod quondam Santius, natus clare memorie Alfonsi, regis Castelle ac Legionis, tunc uiuens, firmiter asserebat fuisse cum ipso et nobili muliere Maria, domina de Molinis, per ipsius predecessoris licteras dispensatum ut, non obstante quod tertio consanguinitatis gradu sibi ad inuicem attinebant, possent iidem Santius et Maria in contracto inter eos matrimonio, uel potius contubernio, licite remanere, 
ipsorumque proles suscepta et suscipienda fuerat legitime nuntiata, collegium ipsum ac nos, qui de collegio tunc eramus, grandi per hoc admiratione, quinimmo turbatione nimirum assumpta, quia pro parte ipsorum Santii et Marie per procuratores seu nuntios fuerat super hoc dispensatio a predicto predecessore petita instanter ac sepius, ac non concessa set expresse negata; et quoniam idem predecessor expresserat pluries, tam in consistorio quam extra, firmiter inter fratres se dispensationem huiusmodi sine ipsorum fratrum consilio aliquatenus non daturum; insuper, quia prefatum collegium, nosque tunc cum ipsis, inter nos ipsos diligentissime conferentes, si de alicuius nostrum conscientia uel notitia talis dispensatio processisset, ac inquisito solerter a camerario, vicecancellario, notariis, auditore contradictarum, correctore, scriptore tenente regestrum aliisque officialibus dicte Sedis qui tempore dicti predecessoris fuerant et tunc erant, per quos apostolice lictere transire solent, si predicte dispensationis lictere de ipsorum uel alicuius eorum conscientia uel notitia transiuissent, nec potuit per quem transiuerint ipse lictere inueniri, habuimus merito dispensationem et licteras que dicebantur a dicto predecessore obtente de falsitate suspectas; postmodum uero, adhuc eadem uacatione durante, capto quodam clerico qui falsitatis huiusmodi fuerat conscius et patrator, et assignato dilecto filio nostro Iohanni, tituli Sanctorum Marcellini et Petri presbitero cardinali, tunc vicecancellario dicte Sedis, fuit idem clericus, cum ab eo per debite inquisitionis officium ueritas peteretur, sponte, sine alia coactione, confessus quod quidam frater Petrus, tunc frater Ordinis Predicatorum, nunc apostata profugus dicti Ordinis, quasdam licteras post obitum prefati predecessoris apud Lateranum falsas conscribi fecit super dispensatione predicta, ipso captiuo, eidem fratri Petro et falsatori licterarum ipsarum scienter in huiusmodi commissione sceleris assistente, quodque ipse captiuus quamdam pecunie quantitatem, quam ab eodem fratre Petro receperat, ipsi falsatori persoluit, et datam apponendam, per eum in dictis falsis licteris in quadam cedula assignauit; et quod postea cum sepedicto fratre Petro usque ad ciuitatem Saone, exitente in Riparia ianuensi, processit, iturus ad prefatum Santium et premium ratione dispensationis huiusmodi recepturus, quod magnum pollicitum fuerat idem frater, sed tandem dictus frater clam discessit ab ipso; vnde auctoritate dicti collegii sollicita fuit diligentia adhibita ut ipse frater, qui huc et illuc discurrebat tanquam sibi male conscius, caperetur. Demum, postquam ad apostolice dignitatis officium misericordia nos diuina prouessit, non inuenimus quod aliquis fratrum uel officialium nostrorum habuerit dispensationis predicte notitiam, ac quod de alicuius eorum conscientia emanasset, nec considerationem nostram preteriit quod, predicto predecessore uiuente, proponebatur quod dicti Santius et Maria non potuerant inuicem matrimonium legitime contraxisse, non solum propter impedimentum consanguinitatis in tertia linea, verum etiam propter spiritualem 
cognationem, quia ipsa Maria filium ipsius Santii, ex alia muliere genitum, de sacro fonte leuauerat, et quia idem Santius cum nobili muliere Guillelma, nata Guasconis de Bierna, sponsalia uel matrimonium ante contraxerat, vnde et ipsa Guillelma repetebat eumdem et separationem eius a dicta Maria postulabat instanter; licet igitur, premissa prouida consideratione pensantes, rationabiliter presumere possint quamuis dispensationem et licteras super ea que dicerentur a sepedicto predecessore obtente, ut liceret ipsis Santio et Marie in dicto matrimonio seu contubernio remanere, uel quod suscepta tunc proles et suscipienda esset legitima, habendas fore de falsitate suspectas; quia tamen ad audientiam nostram peruenit quod lictere que dicuntur super dispensatione predicta a memorato predecessore obtente infrascripti tenoris existunt, scilicet]:

[Nicolaus episcopus, seruus seruorum Dei, dilecto in Christo filio Sancio, illustri regi Castelle et Legionis, et dilecte in Christo filie Marie, vxori eius, salutem et apostolicam benedictionem].

[Proposita nobis humiliter uestra petitio continebat quod inter uos inuicem per uerba de presenti matrimonium contraxistis, non ignorantes quod in tertia linea parentele eratis, ut asseritis, attinentes, et huiusmodi matrimonium fecistis, ut moris est, in Ecclesie facie celebrari. Postea uos, carnali copula subsecuta ac prole suscepta, plurima huiusmodi sic contracti matrimonii precordiali contritione in uestris precepta cordibus inter uos celebrari diuortium uoluistis; cumque enim ex hoc diuortio, si fieret, fratres <inter> consanguineos et carnales amicos uestros alios, personarum et animarum uestrarum et ipsorum regnorum uestrorum pericula multa possent et scandala, sicut per fidedignos recepimus, prouenire, ea nobis, deuotione qua decuit, supplicastis ut de benignitate Sedis Apostolice dispensare misericorditer dignaremur super hoc quod deberetis remanere in dicto matrimonio sic contracto, impedimento taliter nobis exposito non obstante, et prolem exinde susceptam a uobis, uidelicet, Fernandum, uestrum primogenitum et heredem, et Heliçabellam, Petrum, Herricum, de ipsius Sedis legitimare, speciali gratia, curaremus. Nos itaque, cunctis fidelibus, precipue dignitate regia fulgentibus, diuinam et nostram misericordiam implorantibus, deuotione congrua salutis ipsorum animarum desiderio prefulgente, pacem libero animo procurantes, et quantum cum Deo possumus pericula minuere cupientes ac scandala pro uiribus euitare, intellecto inter cetera et percepto per uestras et aliorum licteras quod ex iam percepta precordialissima deuotione expugnare cepistis sarracenos uobis confines, crucis inimicos, et continue laboratis humiliare ac intenditis dare operam iuxta posse pro recuperatione et subsidio Terre Sancte, nunc ab aduersariis fidei catholice occupate, quam Dominus noster Ihesus 
Christus, filius gloriose Marie semper Virginis, pro salute humane generis suo proprio sanguine dedicauit, uestris tam deuotis supplicationibus annuentes, pura, pia et certa causa, auctoritate presentium, dispensamus, ut iam in sic contracto matrimonio, non obstante impedimento prefato, possitis licite remanere, prolem a uobis suceptam, scilicet, Fernandum, uestrum primogenitum et heredem, Eliçabellam, Petrum, Herricum, et si quam aliam ex dicto matrimonio suscepistis, etiam ex speciali gratia ad uberiorem cautelam legitimantes, legitimam reputantes, auctoritate Sedis Apostolice, insuper et censentes super salutari nostro uobis penitentia iniungenda, animabus uestris super hoc decreuimus salubriter prouidendum, concedentes uobis, auctoritate premissa, potestatem et auctoritatem specialem eligendi quem malueritis confessorem qui super hiis et aliis peccatis uestris que sibi confitebimini, data dumtaxat a uobis sufficienti et legitima opera pro recuperatione et subsidio Terre Sancte, iuxta deuotionem a Deo uobis datam, super quo uestram conscientiam duximus onerandam, prefata auctoritate, ad ampliorem gratiam et certiorem cautelam uos super premissis et prolem uestram absoluat et uobis iniungat penitentiam salutarem. Nulli omnino hominum liceat hanc nostram gratiam et dispensationem infringere, aut ei ausu temerario contraire. Si quis autem hanc dispensationem et gratiam nostram attemptare presumpserit, indignationem omnipotentis Dei et beatorum Petri et Pauli, apostolorum eius, et nostram, se nouerit incursurum].

[Datum Rome, apud Sanctam Maria Maiorem, VIII kalendas aprilis, pontificatus nostri anno quinto].

[Quod tenor perspicuis inditiis et uiolentis presuntionibus indicat falsitatem et indubitanter ostendit. Nos, predictis omnibus in considerationem deductis, et aliis que nobis et ipsis fratribus rationabiliter occurrerunt, de eorumdem fratrum consilio, dispensationem et licteras super ea dicti tenoris aut similis, que sub nomine predecessoris prefati dicerentur obtente, et falsitatem ex stilo, dictamine, continentia et aliis que in talibus solent attendi similiter indicarent, quantum ad omnem usum, comodum et effectum duximus suspendendas, omnibus cuiuscumque conditionis, Ordinis, eminentie fuerint, atque status ecclesiastici uel mundani precipientes districtius ut predicti tenoris uel similis dispensatione uel licteris ad quemuis effectum uel comodum non utantur nisi primitus dispensatio ipsa et lictere per Sedem predictam publice fuerint apropbate].

Datum Rome, apud Sanctum Petrum, XII / (f. 372v) kalendas aprilis, [pontificatus nostri] anno tertio. 
Quocirca discretioni uestre, per apostolica scripta mandamus, quatinus uos et uestrum quilibet licteras ipsas, per uos uel alios, in solemnibus ecclesiis $/ 2$ ciuitatum et locis insignibus diocesium uestrorum et alibi ubi expedire uideritis clero et populo public $<\mathrm{e}>$ tis, et eas exponatis et $\mathrm{fa} /{ }^{3}$ ciatis exponi, ut pretendende ignorantie fraudulenter tollatur occasio hiis ad quos notitia licterarum ipsarum peruenerit per pu $/{ }^{4}$ blicationem et expositionem premissas.

Datum Rome, apud Sanctum Petrum, tertio nonas aprilis, [pontificatus nostri] anno tertio. 
